\title{
The suitability of infrared temperature measurements for continuous temperature monitoring in gilts
}

\author{
Mariana Schmidt' ${ }^{1}$ Christian Ammon', Peter Christian Schön², Christian Manteuffel ${ }^{2}$ \\ and Gundula Hoffmann'
}

'Department of Engineering for Livestock Management, Leibniz Institute for Agricultural Engineering PotsdamBornim (ATB), Potsdam, Germany, ${ }^{2}$ Department of Behavioural Physiology, Leibniz Institute for Farm Animal Biology Dummerstorf (FBN), Dummerstorf, Germany

\begin{abstract}
The aim of this study was to evaluate whether an infrared thermometer, a pyrometer, could detect the body surface temperature in the orbital area of gilts without contacting them. Furthermore, it was tested whether an increase in the gilts' temperatures could be detected. Therefore, fever was induced. During 11 trials, 43 German Landrace gilts were injected with either a Porcilis AR-T DF (Intervet International B.V., Boxmeer, Netherlands) vaccine or $2 \mathrm{ml}$ of $0.9 \% \mathrm{NaCl}$. A commercial temperature logger (TRIX-8, LogTag Recorders, Auckland, New Zealand) was placed in the vagina to record temperature data every $3 \mathrm{~min}$. The pyrometer (optris cs, Optris, Berlin, Germany) was aimed at where the orbital area of the gilts would be. While they were drinking, temperature measurements were done in that site by the pyrometer. Time periods from 0.25 to $6 \mathrm{~h}$ were analysed. Considering the $0.25-\mathrm{h}$ period, a positive correlation $(\rho=0.473)$ between temperatures of the logger and the pyrometer was found for 15 of 39 gilts. The longer the chosen measuring period was, the fewer animals showed a significant correlation between the two temperatures. In contrast to the vaginal logger, the pyrometer cannot detect an increase in the body temperature in all fever-induced gilts. In conclusion, a pyrometer cannot detect the body surface temperature reliably. An increase in the body surface temperature over a short time period (on average $5 \mathrm{~h}$ ) could not be detected by the pyrometer. The temperature increase measured using the pyrometer was too low and time-delayed compared to the temperature detected by the vaginal logger.
\end{abstract}

Keywords: infrared thermometer, temperature, sow, gilt, non-invasive

Archiv Tierzucht 57 (2014) 21, 1-12

doi: 10.7482/0003-9438-57-021

Corresponding author:

Gundula Hoffmann; email: ghoffmann@atb-potsdam.de

Department of Engineering for Livestock Management, Leibniz Institute for Agricultural Engineering Potsdam-Bornim (ATB), Max-Eyth-Allee 100, 14469 Potsdam, Germany
Received: 17 December 2014 Accepted: 26 May 2014 Online: 5 August 2014

○) 2014 by the authors; licensee Leibniz Institute for Farm Animal Biology (FBN), Dummerstorf, Germany. This is an Open Access article distributed under the terms and conditions of the Creative Commons Attribution 3.0 License (http://creativecommons.org/licenses/by/3.0/). 
Abbreviations: IRC: infrared camera, PM: pyrometer, VL: vaginal logger, VT: vaginal temperature,

\section{Introduction}

By detecting fever as an early sign of an inflammatory or infectious disease, timely treatment can be provided. To achieve this goal, the authors think, continuous and automatic monitoring is necessary and therefore a highly important topic. In this study, an infrared pyrometer (PM) was used to measure the surface temperature of gilts with fever. This method has the advantage of being non-invasive, contactless and automatically usable, and therefore, it can save time for the staff. In the best case, only the specific sows that were identified as febrile, using the PM, would have to be verified by measuring the rectal temperature by the working staff instead of all or no sows.

Various authors have described the potential of infrared thermography in animals. For example, Johnson et al. (2011) measured the eye temperature of ponies using an infrared camera (IRC), and the results of their study support the use of infrared thermography as an additional method for measuring body temperature. In the study of Traulsen et al. (2010), the temperatures of different body surface locations (eye, inner part of the ear, back of the ear, mammary gland and vulva) were measured to investigate whether infrared thermography is useful to detect the body temperature of gilts. The temperatures were measured using an IRC, with the result that an increase in the rectal temperature corresponded with an increase in infrared temperature. Another study determined that the temperature of the eye of a cow was a useful indicator of its body core temperature (Gloster et al. 2011). Hoffmann et al. (2012) measured the body surface temperatures of cows and calves using an IRC and compared them with the vaginal and rectal temperatures. As a result, they stated that the IRC shows potential as a system for monitoring the body temperatures of cattle.

However, there are potential limitations of infrared measurements and factors that can influence the measurements negative. Therefore, the measurements should be collected out of direct sunlight and wind drafts, hair coats should be free of dirt and moisture, and the effects of weather conditions, circadian rhythms and the time of feeding, milking and lying down should be considered (Knížková et al. 2007). Furthermore, other authors who used the IRC technique for non-continuous measurements concluded that this technique is unreliable in measuring the body temperature or in allowing predictions of the rectal temperature (Chen \& White 2006, Dewulf et al. 2003).

Various body-temperature monitoring systems have been investigated by other authors to find a suitable method for contactless monitoring of animals' body core temperatures. Hillman et al. (2009) used a vaginal logger in cows to measure the body core temperature and compared it to the rectal temperature, and Soede et al. (1997) used a vaginal logger in gilts to measure the body core temperature. Suthar et al. (2013), Stiehler et al. (2013) and Vickers et al. (2010) validated this kind of temperature measuring method. Furthermore, subcutaneous implants in pigs (Lohse et al. 2010) or intraruminal boli in cows (Rose-Dye et al. 2011) have been used in different studies. However, these methods are invasive and carry a certain risk of damage and, therefore, are more suitable for research than for use in husbandry.

The purpose of this study was to automatically detect an increase in the body core temperature via repeated continuous infrared thermography measurements with a PM targeted at the orbital area in fever induced gilts while they were drinking, using the vaginal 
temperature as the control. This control method was validated in a former trial (Schmidt et al. 2013a).

\section{Material and methods}

\section{Animals}

This study was approved by the state office for agriculture, food safety and fisheries in Mecklenburg-Vorpommern (number 7221.3-1.1-005/12), Germany. The trial was conducted in the experimental pig unit of the Leibniz Institute for Farm Animal Biology (FBN), Dummerstorf, Germany with 44 German Landrace gilts from May to December 2012. The gilts were 208 to 215 days of age. Eleven trials were conducted; four gilts were tested in each trial. For the installation of the measurement devices, the animals were maintained on a solid concrete floor without straw bedding, in individual side-by-side crates, leaving one empty crate in between. Each crate measured $0.6 \times 2.2 \mathrm{~m}$. The feed consisted of commercial gilt-rearing feed pellets, and the animals were fed $1300 \mathrm{~g}$ of pellets twice a day. Water was available ad libitum from nipple drinkers.

\section{Treatment}

To induce fever, $2 \mathrm{ml}$ of the commercial vaccine Porcilis AR-T (Intervet International B.V., Boxmeer, Netherlands) (RA vaccine) was administered intra-muscularly once to two gilts that were randomly chosen from four gilts per trial. A dose of $2 \mathrm{ml}$ of $0.9 \%$ sterile $\mathrm{NaCl}$ solution (Selectavet Dr. Fischer GmbH, Weyarn-Holzolling, Germany) was administered in the same way to two control gilts. To acclimatise the gilts to the crates, the treatment was begun on the third day of the trial between 9.00 and 9.30 .

\section{Measurements}

As a control and a more invasive method, the vaginal temperature (VT) of each gilt was measured during the trial. Furthermore, for a contactless method, a fixed pyrometer (optris Cs, Optris, Berlin, Germany) was used to measure the body surface temperature. In addition, the water consumption was measured using a digital flow meter (FCH-m-POM, B.I.O-TECH e.K., Vilshofen, Germany) to detect the exact time and duration of drinking per day, as previously described (Schmidt et al. 2013a). The duration of the drinking period of each gilt was recorded in $\mathrm{s}$. If a pause of $15 \mathrm{~s}$ was detected, a new drinking session was assumed to have started.

The VT was measured continuously. These measurements were performed for three days, from day two through day four of the trial, using a micro-climate monitoring device that was designed for industrial purposes, using an external temperature probe (TRIX-8 recorder with a ST100S-15 probe, LogTag Recorders, Auckland, New Zealand) as a vaginal logger (VL). The logging device and the respective sensor cable were fixed on the backside of the gilts via adhesive tape, and the probe was inserted in the vagina as described in Schmidt et al. (2013a). The VL took temperature data every $3 \mathrm{~min}$. Temperatures below $36^{\circ} \mathrm{C}$ were excluded from the data evaluation because they indicated that the VL had slipped out of the vulva, e.g., due to excretion, as no increase of temperature above that threshold was found after dropping 
below $36^{\circ} \mathrm{C}$ without manually reinserting the VL. As soon this event was noticed, the VL was cleaned and reinserted. Because a staff person was present only during the day time, $V L$ data for the night time was rarely available for many of the gilts; during 35 of the in total 84 observed sows and nights the logger slipped out.

In the 5th trial, one gilt in the control group did not drink at all during the treatment period, and therefore, this gilt was excluded from further evaluation. In the 10th trial, a malfunction occurred in the VL of one of the gilts in the control group. The data from this gilt could not be used for further evaluation.

The emissivity of human skin, $\varepsilon=0.985$, was used for the infrared device. The PM was secured in the neighbouring empty pen, and the target area of the gilt was the orbital area (Figure 1). The distance between the body surface and the pyrometer was approximately $20-30 \mathrm{~cm}$, which resulted in a measuring spot diameter of 1.3 to $2.0 \mathrm{~cm}$. The PM measured continuously with a system accuracy of $\pm 1.5^{\circ} \mathrm{C}$. The temperature data that were used for evaluation were those taken only when the gilt was drinking, to ensure that the PM had been aimed at the orbital area. Temperature measurements lower than $35^{\circ} \mathrm{C}$ were discarded because those values indicated that the sows had moved outside the target area of the PM and therefore the measurements were not measurements of the orbital area. Based on findings in a previous study analysing infrared measurement methods in various body locations (Schmidt et al. 2013b) the threshold of $35^{\circ} \mathrm{C}$ was chosen by subtracting twice the accuracy of the PM from the lower end of the expected temperature range in pigs of $38^{\circ} \mathrm{C}$. The following monitoring periods: $0.25 \mathrm{~h}, 1 \mathrm{~h}, 2 \mathrm{~h}, 3 \mathrm{~h}, 4 \mathrm{~h}$ and $6 \mathrm{~h}$ were chosen for monitoring. For every period the maximum temperatures were calculated in both devices, VL and PM. These intervals were chosen because of the following different reasons. Accordingly, a change in the temperature should be detected as early as possible, which requires short measurement intervals, and it should be possible to follow the change in temperature over the long term, which might be easier in longer intervals, as taking only the maximum temperature in every period will smoothen the shape of the temperature curve. Due to their circadian rhythms, long periods occur during which the animals do not drink at all, which also is an indication for using longer periods to increase the chance to have at least one temperature measurement within that period.

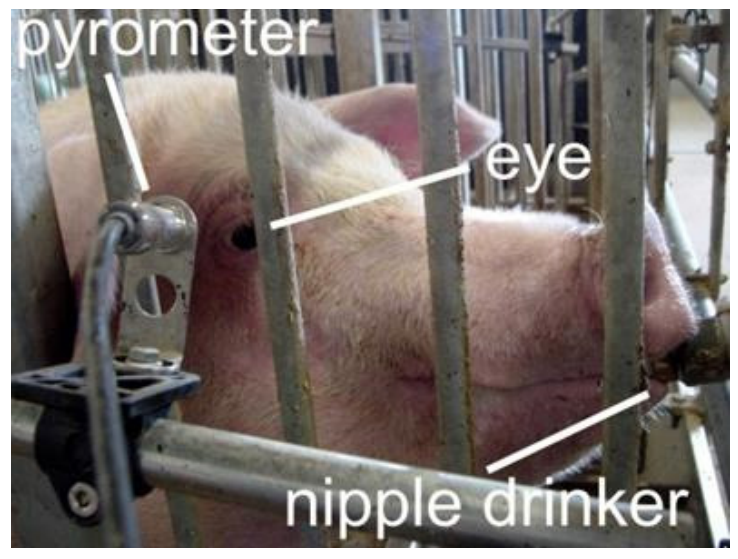

Figure 1

Arrangement of the pyrometer, nipple drinker and sow 


\section{Statistical analysis}

Statistical analysis was performed using the SAS v. 9.3 software (SAS Institute Inc., Cary, NC, USA). To achieve an initial overview, the Pearson correlation between the vaginal temperature and the pyrometer temperature was calculated for each of the gilts and for each of the six monitoring periods mentioned above, based on the maximum values per time period for each measurement method. For comparison, the pooled Pearson correlations between the VL and PM temperatures for all gilts and for each monitoring period were calculated as well. Overall variation of temperature measurements by period was charted in a Bland-Altman plot (Bland \& Altman 1999).

A mixed linear model was used with the MIXED procedure in SAS to compare the ability of two methods (VL and PM) to detect changes in maximum temperature (T) while considering the following factors: measurement method, monitoring period, time of the day, treatment group, vaccine influence and animal effect. The fixed effects were the method (MTH, with $i=2$ levels, for the VL and the PM), the monitoring period during a day (MID, with $j=96, j=24$, $j=12, j=8, j=6$ and $j=4$ levels for the variants of the 0.25 -h period, 1-h period, 2-h period, 3-h period, 4-h period and 6-h period, respectively), the treatment group (GRP, with $\mathrm{k}=2$ levels for the vaccine treatment and the $\mathrm{NaCl}$ control groups) and the period of treatment effect during the day (VAC, with $\mathrm{I}=2$ levels for the data obtained between 8.00 and 21.00 on the third day of the trial and for all of the other data). A random effect of the gilts (GLT, $\mathrm{m}=1, \ldots, 42$ ) that was grouped by the method was included. Repeated measurements for a gilt that were grouped by the method were considered using a spatial power covariance structure. This technique allowed accounting for correlated measurements for a gilt based on differences in the monitoring periods when the data were not evenly spaced in time because there were missing data, e. g., when the gilts did not drink or when the VL slipped out of the vulva for a prolonged period of time.

Because interactions between the fixed effects were expected, the full model including all of the interactions was fitted first, separately for each of the six monitoring periods. Effects that were not significant $(>5 \%)$ in at least one of the monitoring periods were then excluded from the model. The resulting model equation was as follows:

$$
\begin{aligned}
& T_{i j k l m n}=\mu+M T H_{i}+M I D_{j}+(M T H \times M I D)_{i j}+G R P_{k}+V A C_{l}+(M T H \times V A C)_{i l}+(M I D \times V A C)_{j l}+ \\
& (M T H \times M I D \times V A C)_{i j l}+(M T H \times G R P \times V A C)_{i k l}+(M I D \times G R P V A C)_{j k l}+G L T(M T H)_{i m}+\varepsilon_{i j k l m n}
\end{aligned}
$$

where $T$ is the observed maximum temperature, $\mu$ is the general mean of temperature, MTH is fixed effect of method, MID is the fixed effect of measuring interval during a day, $M T H \times M I D$ is the fixed interaction effect between method and measuring interval, GRP is the fixed effect of treatment group, VAC is the fixed effect of treatment period, MTH $\times V A C$ is the fixed interaction effect between method and treatment period, MID $\times V A C$ is the fixed interaction effect between measuring interval and treatment period, $M T H \times M I D \times V A C$ is the fixed interaction effect between method, measuring interval and treatment period, $M T H \times G R P \times V A C$ is the fixed interaction effect between method, treatment group and treatment period, MID $\times G R P \times V A C$ is the fixed interaction effect between measuring interval, treatment group and treatment period, $G L T(M T H)$ is the random effect of gilt nested within method and $\varepsilon$ is the random residual. 
The factor estimates from the models as well as their standard errors were then used to plot the mean curves of maximum temperatures over a day and the corresponding $95 \%$ confidence intervals by each period, for both measurement methods and for the time of the day under vaccine influence.

To calculate the average differences between the day and night temperatures according to the method and the measuring period as well as the average differences between treatment group and control group during vaccine influence according to the method and the measuring period, the required contrasts were established using the LSMESTIMATE statement. Degrees of freedom were approximated with the method by Kenward \& Roger (1997).

For the 1-h and $0.25-\mathrm{h}$ periods no solutions for the required linear contrasts were found.

\section{Results}

A significant positive correlation between the VL and PM temperatures was found in $38.5 \%$, $34.2 \%$ and $28.9 \%$ of the animals when intervals of $0.25 \mathrm{~h}, 1 \mathrm{~h}$ and $2 \mathrm{~h}$ were used, respectively (Table 1). The longer the chosen interval, the fewer animals provided a significant correlation between the $V L$ and PM temperatures. The lowest ranges $(0.169,0.176)$, interquartile ranges $(0.076,0.038)$ and high medians $(0.726,0.772)$ were found when intervals of $2 \mathrm{~h}$ and $3 \mathrm{~h}$ were used, respectively. Figure 2 shows Bland-Altman plots of the overall variation for each period. The figure shows that the difference of PM and VL temperatures have a tendency toward $0{ }^{\circ} \mathrm{C}$ with higher arithmetic means of both temperatures.

Table 1

Overview of the period, the number of gilts and the measurements, with the median, $25 \%$ (Q25) and $75 \%$ quantile (Q75) of the individually significant Pearson correlations $\left(\rho_{i}\right)$ as well as pooled Pearson correlations $(\rho)$ with corresponding $P$-values (t-test, $n$ - 2 degrees of freedom)

\begin{tabular}{lccccccc}
\hline & \multicolumn{6}{c}{ Period, $\mathrm{h}$} \\
& 0.25 & 1 & 2 & 3 & 4 & 6 \\
\hline Number of gilts & 39 & 38 & 38 & 38 & 34 & 40 \\
Minimum measurements per gilt & 6 & 6 & 6 & 6 & 5 & 3 \\
Number and percentage of gilts & 15 & 13 & 11 & 5 & 7 & 5 \\
with a significant correlation & $(38.5 \%)$ & $(34.2 \%)$ & $(28.9 \%)$ & $(13.2 \%)$ & $(20.6 \%)$ & $(12.5 \%)$ \\
\hline \multicolumn{1}{c}{$\quad$ Q25 } & 0.463 & 0.526 & 0.716 & 0.762 & 0.694 & 0.843 \\
$\rho_{\mathrm{i}} \quad$ Median & 0.509 & 0.569 & 0.726 & 0.772 & 0.787 & 0.846 \\
& $\quad$ Q75 & 0.635 & 0.655 & 0.791 & 0.8 & 0.883 & 0.938 \\
\hline$\rho$ & 0.462 & 0.513 & 0.246 & 0.157 & 0.348 & 0.208 \\
$P$-value & 0.002 & 0.021 & 0.418 & 0.644 & 0.359 & 0.001 \\
\hline
\end{tabular}

As seen in Figure 3, an increase of the temperature was detected with the VL in all of the monitoring periods. This increase lasted on average $5.13 \mathrm{~h}$ as described before (Schmidt et al. 2013a). A significant increase in the PM temperature of the corresponding group was not detectable. Furthermore, the increase in the PM temperature occurred with a time delay 


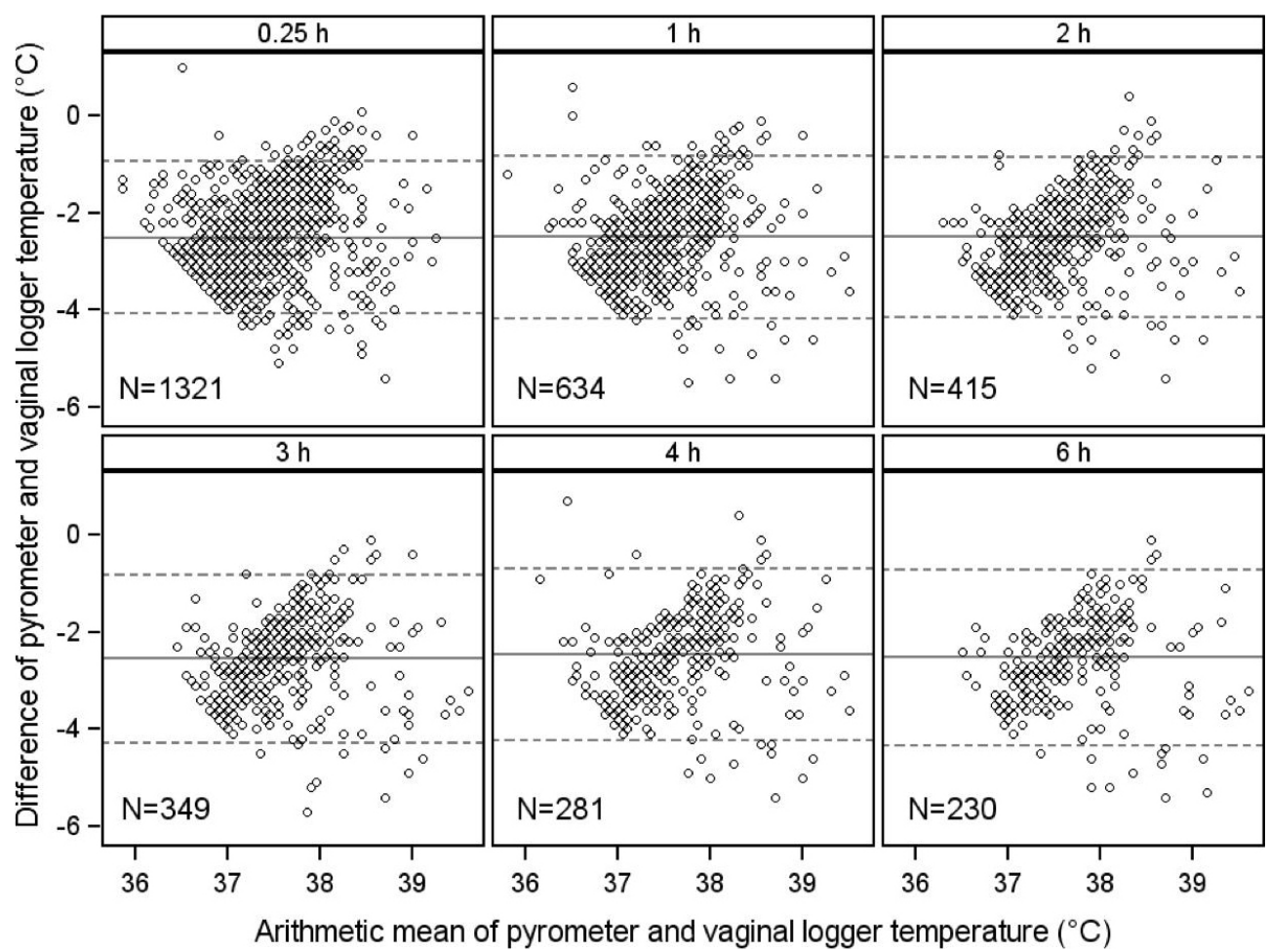

Figure 2

Bland-Altman plot for pooled data of 42 gilts for each of the monitoring periods, each showing mean difference between pyrometer and vaginal logger measurements \pm 1.96 standard deviations

compared to the temperature measured with the VL. It can be seen that the smaller the period was, the higher the variability.

Table 2 shows the differences between the PM temperatures of the vaccinated gilts on the control day (no vaccination) and the day of the vaccination. As seen, the temperature differences did not significantly change in accordance with the length of the measuring periods.

Table 2

Mean differences in the pyrometer temperatures of the gilts in the treatment group $(n=21)$ between the vaccination period and control period by time period, estimated with linear contrasts using the data taken from the results of the statistical model and tested with t-test $(\alpha=0.05$, degrees of freedom approximated with the method by Kenward \& Roger [1997])

\begin{tabular}{lccccc}
\hline Time period, $\mathrm{h}$ & $\begin{array}{c}\text { Mean } \\
\text { difference, }{ }^{\circ} \mathrm{C}\end{array}$ & $\begin{array}{c}\text { Standard error, } \\
{ }^{\circ} \mathrm{C}\end{array}$ & $\begin{array}{c}\text { Total number of } \\
\text { measurements }\end{array}$ & $\begin{array}{c}\text { Degrees of } \\
\text { freedom }\end{array}$ & $P>|t|$ \\
\hline 2 & 0.12 & 0.19 & 189 & 60.95 & 0.51 \\
3 & 0.16 & 0.20 & 131 & 71.42 & 0.42 \\
4 & 0.14 & 0.21 & 112 & 71.03 & 0.50 \\
6 & 0.21 & 0.22 & 54 & 89.90 & 0.35 \\
\hline
\end{tabular}




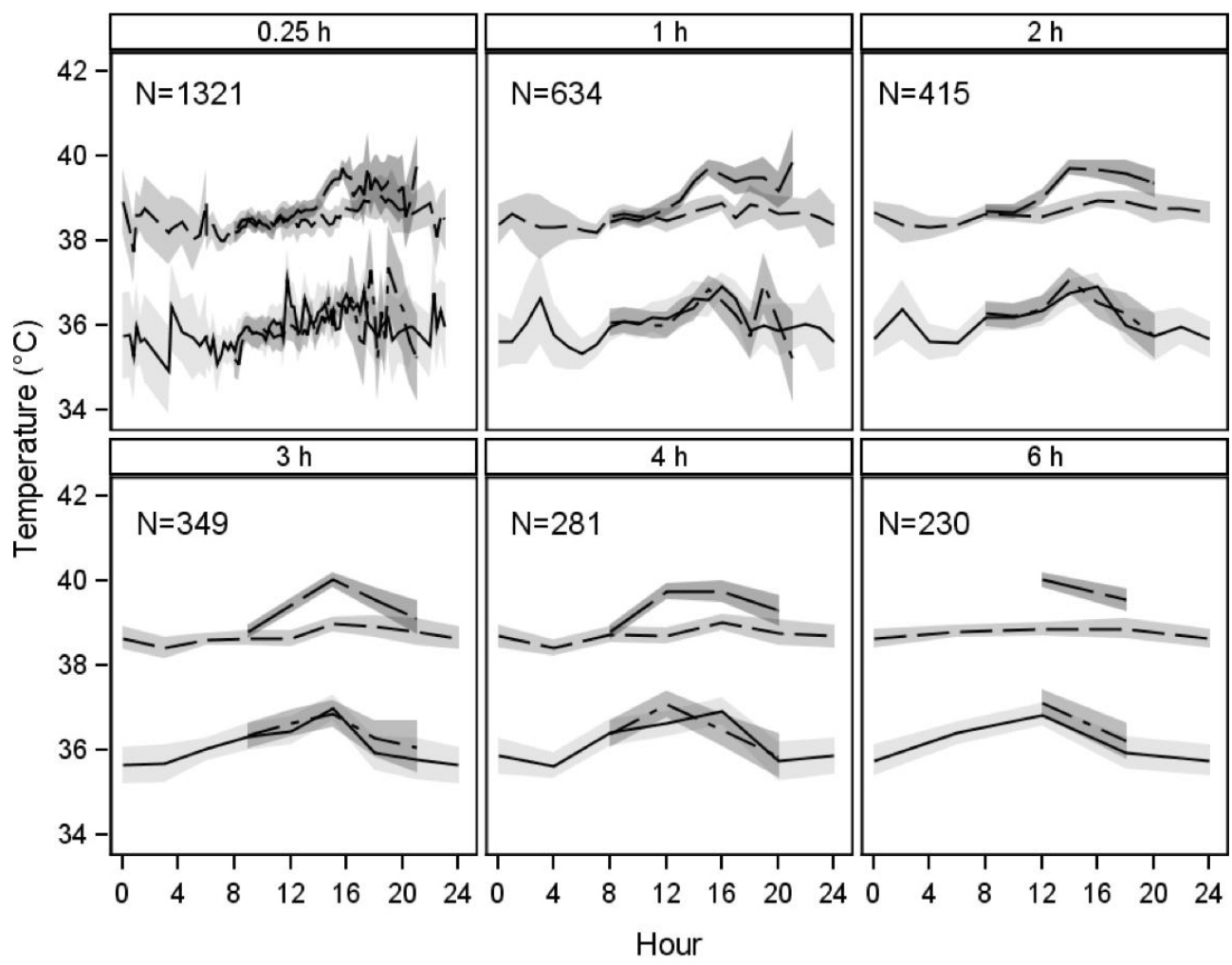

PM, no vaccine influence $---\mathrm{VL}$, no vaccine influence
-- - PM, during vaccine influence
-

Bands show the $95 \%$ confidence interval of the mean

Figure 3

24-h overview of the temperatures of all of the gilts in the treatment group $(\mathrm{N}=21)$ taken using the pyrometer (PM) and the vaginal logger (VL)

Table 3

Average difference between the day and night temperatures (excluding the time of vaccination) according to the method and the measuring period based on data of 42 gilts; day $=6.00$ to $<18.00$, night $=18.00$ to $<6.00$

\begin{tabular}{|c|c|c|c|c|c|c|}
\hline \multirow[t]{2}{*}{ Period, $\mathrm{h}$} & \multirow{2}{*}{$\begin{array}{l}\mathrm{N} \text { per } \\
\text { method }\end{array}$} & \multirow[t]{2}{*}{ Method } & \multirow{2}{*}{$\begin{array}{l}\text { Estimated temperature } \\
\text { difference day - night }\end{array}$} & \multicolumn{2}{|c|}{$95 \%$ confidence interval } & \multirow{2}{*}{$\begin{array}{c}\text { Adjusted } \\
P \text {-value }\end{array}$} \\
\hline & & & & Lower & Upper & \\
\hline \multirow{2}{*}{6} & \multirow{2}{*}{252} & PM & 1.66 & 1.19 & 2.14 & $<0.001$ \\
\hline & & VL & 0.05 & -0.12 & 0.21 & 0.761 \\
\hline \multirow{2}{*}{4} & \multirow{2}{*}{312} & PM & 2.84 & 2.14 & 3.53 & $<0.001$ \\
\hline & & VL & 0.34 & 0.08 & 0.60 & 0.009 \\
\hline \multirow{2}{*}{3} & \multirow{2}{*}{378} & PM & 2.49 & 1.57 & 3.42 & $<0.001$ \\
\hline & & VL & 0.17 & 0.00 & 0.34 & 0.050 \\
\hline \multirow{2}{*}{2} & \multirow{2}{*}{466} & PM & 3.98 & 2.63 & 5.34 & $<0.001$ \\
\hline & & VL & 0.20 & 0.04 & 0.36 & 0.011 \\
\hline
\end{tabular}


For both of the methods and all of the periods, there was a significant difference between the average day and average night temperatures, except for the VL measurements over the 3-h and 6-h periods (Table 3). The $P$-values for all of the PM measurements were close to zero, and the estimated temperature differences for every set of PM measurements were higher than for the VL measurements. The smallest difference between the day and night measurements was found when using a 6 -h period.

The arithmetic mean value of the daily duration of drinking was $8.12 \mathrm{~min}(\mathrm{~N}=44)$ and the standard deviation was 6.34 min per day.

\section{Discussion}

As other studies have shown, temperature measurements taken with a rectal thermometer are often not accurate because of an inadequate insertion depth of the thermometer (Naylor et al. 2012). Stiehler et al. (2013) demonstrated that rectal temperature is a repeatable diagnostic method in sows, when the method is standardized and when the penetration depths and the type of thermometer is taken into account. Taking measurements with a fixed VL can be used as a method to measure the body temperature in dairy cows (Suthar et al. 2013) and in gilts (Schmidt et al. 2013a). This method provides the advantage of continuous measurements for experimental studies, and a previous study showed that the VT correlated with the rectal temperature in sows (Schmidt et al. 2013a). However, a limitation of the VL was the high percentage of slipped-out loggers. A better vaginal fixation would be useful, but also more invasive and with the risk of injuries, what should be avoided in the gilts of this study because of following breeding processes.

Confined sows and outdoor sows spend only $2.1 \%$ (approximately $0.5 \mathrm{~h}$ ) and $0.5 \%$ (approximately $7 \mathrm{~min}$ ) of the day drinking, respectively (Hötzel et al. 2005). In our study, the arithmetic mean value of the drinking duration of the gilts was $0.6 \%$ (approximately $8 \mathrm{~min}$ ) of the day. This is less time in comparison to that spent by the confined sows that were examined by Hötzel et al. (2005). One reason why our results differ from the results of other authors could possibly be a different water flow rate $(50 \mathrm{ml} / \mathrm{s}$ in our trials). Therefore, the 0.25 -h period is very short and will lead to much missing temperature data during the day because sows do not drink at regular time periods. For continuous temperature monitoring, periods of $2 \mathrm{~h}$ appear to be more useful because the corresponding correlation coefficients were higher and more exact compared to those for the shorter periods. However, the number of gilts showing significant correlation between the $\mathrm{VL}$ and PM temperatures was lower (only 11 of 38 gilts). In contrast, the 0.25 -h period yielded the highest number of gilts with significant correlations between their VL and PM temperatures ( 15 out of 39 gilts). This can be explained to a certain extent by having more pairs of data available in shorter periods, which is less likely to produce significant results, but in our case leads to lower absolute correlations due to the fluctuations between the different times of the day, especially for the PM (see also Figures 2 and 3). In longer periods there is less fluctuation between different times of the day, as due to our approach to use only the maximum temperature in every period the shape of the maximum temperature curve throughout the day is smoothened. The lower number of values in the longer periods will make it more difficult to find significant correlations, but often the smoothing effect will lead to higher absolute correlation values. 
Independent of the period, the variability of the measurements taken with the PM was too high to detect the occurrence of low temperature differences.

There was a significant difference between the average day and night temperatures obtained using both methods and in all of the periods, as shown in table 3, except for the VL measurements with the 3-h and 6-h periods. However, the $95 \%$ confidence limits showed that the average differences between the day and night temperatures that were measured with the $\mathrm{VL}$ did not exceed $0.6 \mathrm{~K}$, whereas they were at least $1.19 \mathrm{~K}$ for the PM measurements. This result implies that there was a much stronger diurnal rhythm in the temperature measurements with the PM than in the measurements with the VL, which must be considered when using a PM for temperature monitoring. The reason for the stronger diurnal rhythm in the PM measurements could be that the core temperature is regulated more strictly than is the surface temperature. When considering a monitoring system, this fact needs to be taken into account. Detecting an increase in the body surface temperature that correlated with an increase in the core temperature was not possible. Changes in the temperature level could likely be better detected if they were large and/or sufficiently prolonged. A better accuracy of the PM could also improve the results, because the system of this study works with an accuracy of $\pm 1.5^{\circ} \mathrm{C}$. The PM appeared to be unsuitable for detecting short-term temperature increases and decreases within the period of $12 \mathrm{~h}$ postvaccination because the variability in its measurements compared to that of the VL was too high. However, the induced temperature increase should have lasted for at least $12 \mathrm{~h}$, so the effect of the circadian rhythm would not have such a strong influence, and the PM detected a higher temperature level over a longer period than during the previous days. Furthermore, the animals drank less during the night, and hence, the standard error for the measurements taken during the night was higher compared to that for the measurements taken during the day. These results partially agree with the results of other authors. Franze et al. (2012) found no correlations between the infrared temperatures of the lower leg areas that were measured using an infrared camera and the rectal temperatures of cows. Another study conducted with humans showed that the sensitivity-specificity combination might not be high enough for screening febrile conditions using an infrared thermography camera aimed at the forehead (Chan et al. 2013). In contrast, Traulsen et al. (2010) concluded that infrared thermography provided the opportunity to collect regular body surface temperatures. However, it must be noted that all of these authors performed the infrared measurements using an infrared camera with which extremely good targeted measurements are possible, whereas in our study, a PM was used and the measurement spot was more variable. In addition, the other authors used one-time measurements, whereas in this study, continuous measurement was applied. Furthermore, the PM was permanently installed, whereas the infrared camera had been aimed at the target area for each measurement. Therefore, it is not certain whether the PM was always aimed at the same intended target (the eye) but may have been instead aimed only at the greater spot at the orbital area, which would lead to a lower correlation with the VL data due to comparing different body-surface locations with differing surface temperatures at every point in time. In a former study, locations which also represented adequate results were mamma and vulva (Schmidt et al. 2013b). But because of the positioning of the animals and the practicability of measuring, these locations proved as not adequate. 
Six different time periods were utilised in this study. The data from the 0.25 -h and 1 -h periods showed very high variability compared to that from the periods of 2-h, 3-h and 4-h (Figure 2). However, a change in temperature does not occur as rapidly (e.g., in approximately $15 \mathrm{~min}$ ), and furthermore, the surface temperature most likely reacts more slowly compared to the central regulation systems. If the chosen period was shorter $(15 \mathrm{~min}, 1 \mathrm{~h})$ the variability in the temperature data was higher.

In conclusion, a short-duration increase in the body surface temperature could not be detected automatically with the PM in the orbital area of fever-induced gilts, as opposed to the increase in the body core temperature that was measured using the VL. This result might be different for longer term temperature increases, which would require additional animal experiments or more extensive on-farm studies with naturally occurring inflammatory or infectious diseases that lead to longer feverish periods. The PM measurements were subject to a more noticeable circadian rhythm compared with the VL measurements.

\section{Acknowledgements}

The authors thank the staff of the experimental pig unit Dummerstorf for their assistance. This project was supported by funds of the German Federal Ministry of Food, Agriculture and Consumer Protection (BMELV) via the Federal Office for Agriculture and Food (BLE) in the framework of the innovation support program.

\section{References}

Bland JM, Altman DG (1999) Measuring agreement in method comparison studies. Stat Methods Med Res 8, $135-160$

Chan LS, Lo JLF, Kumana CR, Cheung BMY (2013) Utility of infrared thermography for screening febrile subjects. Hong Kong Med J 19, 109-115

Chen PH, White CE (2006) Comparison of Rectal, Microchip Transponder, and Infrared Thermometry Techniques for Obtaining Body Temperature in the Laboratory Rabbit (Oryctolagus cuniculus). JAALAS 45, 57-63

Dewulf J, Koenen F, Laevens $\mathrm{H}$, de Kruif A (2003) [Infrared thermometry is not suitable for the detection of fever in pigs]. Vlaams Diergeneeskd Tijdschr 72, 373-379 [in Dutch]

Franze U, Geidel S, Heyde U, Schroth A, Wirthgen T, Zipser S (2012) [Investigation of infrared thermography for automatic health monitoring in dairy Cows]. Züchtungskunde 84, 158-170 [in German]

Gloster J, Ebert K, Gubbins S, Bashiruddin J, Paton DJ (2011) Normal variation in thermal radiated temperature in cattle: implications for foot-and-mouth disease detection. BMC Vet Res 7:73

Hillman PE, Gebremedhin KG, Willard ST, Lee CN, Kennedy AD (2009) Continuous measurements of vaginal temperature of female cattle using a data logger encased in a plastic anchor. Appl Eng Agric 25, 291-296

Hoffmann G, Schmidt M, Ammon C, Rose-Meierhöfer S, Burfeind O, Heuwieser W, Berg W (2013) Monitoring the body temperature of cows and calves using video recordings from an infrared thermography camera. Vet Res Commun 37, 91-99

Hötzel MJ, Machado Filho LCP, Dalla Costa OA (2005) Behaviour of pre-parturient sows housed in intensive outdoor or indoor systems. Pesq Agropec Bras 40, 169-174

Johnson SR, Rao S, Hussey SB, Morley PS, Traub-Dargatz JL (2011) Thermographic Eye Temperature as an Index to Body Temperature in Ponies. J Equine Vet Sci 31, 63-66 
Kenward MG, Roger JH (1997) Small Sample Inference for Fixed Effects from Restricted Maximum Likelihood. Biometrics 53, 983-997

Knížková I, Kunc P, Gürdil GAK, Pinar Y, Selvi KC (2007) Applications of infrared thermography in animal production. OMÜ Zir Fak Dergisi 22, 329-336

Lohse L, Uttenthal Å, Enøe C, Nielsen J (2010) A study on the applicability of implantable microchip transponders for body temperature measurements in pigs. Acta Vet Scand 52: 29

Naylor JM, Streeter RM, Torgerson P (2012) Factors affecting rectal temperature measurement using commonly available digital thermometers. Res Vet Sci 92, 121-123

Rose-Dye TK, Burciaga-Robles LO, Krehbiel CR, Step DL, Fulton RW, Confer AW, Richards CJ (2011) Rumen temperature change monitored with remote rumen temperature boluses after challenges with bovine viral diarrhea virus and Mannheimia haemolytica. J Anim Sci 89, 1193-1200

Schmidt M, Ammon C, Schon P, Manteuffel C, Hoffmann G (2013a) Assessment of continuous vaginal loggerbased temperature monitoring in fever-induced gilts. Am J Anim Vet Sci 8, 55-65

Schmidt M, Lahrmann KH, Ammon C, Berg W, Schön P, Hoffmann G (2013b) Assessment of body temperature in sows by two infrared thermography methods at various body surface locations. J Swine Health Prod 21, 203-209

Soede NM, Hazeleger W, Broos J, Kemp B (1997) Vaginal temperature is not related to the time of ovulation in sows. Anim Reprod Sci 47, 245-252

Stiehler T, Heuwieser W, Pfützner A, Voigtsberger R, Burfeind O (2013) [Repeatability of measurements of the rectal temperature and comparison of vaginal and rectal temperature in puerperal sows]. Tierarztl Prax 41, 217-224 [in German]

Suthar V, Burfeind O, Maeder B, Heuwieser W (2013) Agreement between rectal and vaginal temperature measured with temperature loggers in dairy cows. J Dairy Res 80, 240-245

Traulsen I, Naunin K, Müller K, Krieter J (2010) Application of infrared thermography to measure body temperature of sows. Züchtungskunde 82, 437-446

Vickers LA, Burfeind O, von Keyserlingk MAG, Veira DM, Weary DM, Heuwieser W (2010) Technical note: Comparison of rectal and vaginal temperatures in lactating dairy cows. J Dairy Sci 93, 5246-5251 